\title{
LOPES, Ana Mónica; ARNAUT, Luís. História da África: uma introdução. Belo Horizonte: Crisálida, 2005.
}

\section{José Alexandre da Silva:}

Desde 2003, quando o Presidente Lula sancionou a lei $\mathrm{n}^{\circ} 10.639$, vários títulos dedicados à história afro-brasileira e africana têm surgido no mercado editorial brasileiro. O conteúdo da referida lei torna obrigatório o ensino de História Africana e Afro-brasileira nas escolas públicas e particulares de nosso país. Nesse sentido, ela cria uma demanda de materiais que sirvam de subsídio para professores da Educação Básica, alunos de graduação e a quem mais interessar. Uma das formas em que o mercado editorial vem respondendo a essa necessidade é trazendo a público livros de caráter introdutório. ${ }^{1}$

Uma dessas obras é História da África: uma introdução. De autoria de Ana Mónica Lopes, africana nascida em Lubango, doutora em História das Culturas, e Luís Arnaut, professor de História da África na Universidade Federal de Minas Gerais (UFMG). Este livro de dimensões modestas visa introduzir o leitor ao conhecimento acerca da história

\footnotetext{
* Professor de História da Secretaria de Estado de Educação do Paraná, e mestrando em educação pela Universidade Estadual de Ponta Grossa (UEPG). E-mail: sjosealexandre@ymail.com

${ }^{1}$ Sobre algumas dessas obras traçamos algumas reflexões: SILVA, José Alexandre. África e Brasil Africano para a sala de aula. Históriae-História. In: http://www. historiaehistoria.com.br/materia.cfm?tb=resenhas\&id $=21$; Ancestrais: uma introdução à História da África Atlântica. Revista África e Africanidades. Ano I - n. 4 - Fev. 2009. In: http://www.africaeafricanidades.com/documentos/ Ancestrais_uma_introducao_a_historia_da_Africa.pdf
}

304 Revista de História Regional 16(1): 304-310, Verão, 2011 
da África. Não obstante, cumpre seu papel construindo um panorama do continente amparado em pesquisadores brasileiros e africanos e, seu principal mérito, traz as principais concepções historiográficas acerca do continente africano.

A conquista dos movimentos negros que representa essa lei, a nosso ver, passa por alguns dilemas. Embora algumas unidades da federação organizadas com suas Secretarias de Educação, oficialmente possuam um discurso no sentido de efetivar a lei, é outra história afirmar que ela seja de fato levada até seu objetivo final, a sala de aula. Quando se fala de história africana, logo nossas lembranças escolares nos remetem à história da escravidão, com as imagens de negros em ambiente de trabalho ou sendo açoitados. Pensando na história da África, o conteúdo escolar mais recorrente é o das navegações do século XVI, quando portugueses e holandeses contornam o continente. Essa visão repousa na representação do dominador, civilizado e possuidor de um aparato tecnológico mais sofisticado, o europeu. Em contrapartida, temos a representação do africano submisso, colonizado e destituído de objetos que remetam à ideia de tecnologia. Assim, a visão mais difundida da África continente torna-se um obstáculo.

Ao longo do tempo, esses elementos presentes nos materiais escolares e nas salas de aulas, se cristalizaram em nosso imaginário. Romper com a narrativa do negro vitimizado vindo de um lugar desconhecido pode ser um passo essencial para que os afrodescendentes se assumam como tal. Entretanto, também é importante lembrar que construir uma narrativa na qual os africanos e os afro-brasileiros figurem de forma digna não significa fomentar ódio racial ou um país cindido entre brancos e negros. ${ }^{2}$ Nosso país é composto por várias etnias, e que cada uma tenha sua história não implica em animosidade entre as mesmas.

Já na introdução da obra, os autores justificam a necessidade de seu livro apresentando a questão de como os

\footnotetext{
${ }^{2}$ Este argumento é defendido por alguns autores, entre os quais destacamos: MAGNOLI, Demétrio. Uma Gota de Sangue. São Paulo: Contexto, 2009. Ver: SILVA, José Alexandre. Históriae-História. In: http://www.historiaehistoria. com.br/materia.cfm?tb=resenhas $\&$ id $=60$
} 
professores ensinarão a seus alunos algo que não aprenderam nos bancos da universidade, considerando que nos cursos de licenciatura o continente aparece como secundário e marginal em relação a alguns processos históricos. No primeiro capítulo, são abordadas as várias construções acerca da ideia de África, em fontes como os textos de Heródoto, Plínio e a cartografia medieval, desde o período da Antiguidade, passando pela Idade Média e Moderna. No geral, prevalece a noção de "território de monstros", continente associado ao "Bestiário" e região de "clima inóspito".

O segundo capítulo questiona o termo África que, utilizado de forma genérica, como identidade estabelecida pelo europeu, para todos os habitantes do continente não permite uma matização de suas diferenças fisicas, culturais e sociais, tendo sido utilizado como sinônimo de atraso. Os autores pontuam que os habitantes da África devem ser pensados como membros de civilizações e culturas que realizaram migrações, trocas culturais com outras civilizações e com padrões de sociabilidade que tornam inadequadas sua caracterização pela ótica ocidental. Há que se destacar a importância da reflexão empreendida pelos autores sobre os conceitos de raça, etnia e formação humana.

No capítulo 3, intitulado "Religiões", Lopes e Arnaut traçam um perfil do continente africano no que tange a essa questão. A introdução das religiões monoteístas, como o cristianismo e o islamismo, é analisada de forma atenta pelos autores, os quais destacam que esta última se encontra na melhor posição para se tornar a religião do continente, devido ao seu ritmo de crescimento. No que se refere às religiões nativas, consideramos importante citar: "[...] tentam responder às mesmas indagações que as demais religiões. Apresentam um deus superior que criou o universo e, em algumas, verificamos a presença de entidades menores [...] Outro elemento importante é a ligação com os ancestrais [...].” 3

O quarto capítulo trabalha a questão de como as diferentes tradições intelectuais se posicionaram diante

\footnotetext{
${ }^{3}$ LOPES, Ana Mónica; ARNAUT, Luís. História da África: uma introdução. Belo Horizonte: Crisálida, 2005, p. 30-31.
}

306 Revista de História Regional 16(1): 304-310, Verão, 2011 
do continente africano. A concepção hegeliana de negação de história para a África prevaleceu favorecida pela noção, superada, de se considerar o que é histórico vinculado ao surgimento da escrita. Nos dias de hoje, acredita-se que a humanidade está vinculada ao princípio da ereção corporal que possibilitou pensar outros registros, iconográficos e artísticos, como fontes de pesquisa. Os autores também mencionam a importância de alguns centros de pesquisa, que mesmo estando atrelados ao colonialismo europeu, deram uma contribuição importante para aspectos da história e geografia africana, assim como a realização do projeto História Geral da África coordenado pela na década de 1960.

O quinto capítulo versa sobre as organizações políticas. Nele, os autores trabalham com categorias de império e reinos e classificam a organização política dos povos africanos em três fases distintas até o período da colonização. Uma se estende até o século VI da era cristã, marcada pela constituição de grandes culturas na faixa mediterrânea e na extensão do Nilo. Uma segunda até o século XV, marcada pela presença islâmica. A terceira fase vai até 1880 e é caracterizada pela presença europeia no continente.

O capítulo 6 é referente ao fenômeno que chamamos também de neocolonialismo. Até o final do século XIX, o contato dos europeus com o continente africano estava mais restrito ao litoral. Com as independências das nações latino-americanas, voltaram sua atenção para continente que até então funcionava principalmente como repositório de escravos, partilhando-o entre si. As explicações mais comuns para esse fenômeno são realizadas a partir da perspectiva europeia, com a concentração de capital e formação de monopólios nos países colonizadores.

O livro aqui analisado traz uma perspectiva diferente, amparada na teoria da dimensão africana. Segundo essa, uma expansão do capital privado desencadeou uma ocupação militar no continente africano frente à ação de resistência dos habitantes nativos à colonização. Os europeus de fato tiveram motivos de ordem econômica para essa expansão, 
mas os povos do continente africano também estavam passando por transformações antes da presença europeia, de modo que a resistência dessas populações ao domínio comercial desencadeou o domínio militar. Essa resistência é categorizada pelos autores em: primária, primária retardada e intermediária. Em suas palavras:

A resistência primária foi uma reação direta à ameaça representada pelos invasores europeus. Os reis buscavam através dos diversos meios disponiveis, tanto militares quanto diplomáticos, conter a invasão, ou pelo menos impedir que resultasse na extinção dos reinos. Após os europeus já terem estabelecido sua presença e sua autoridade no território africano, desenvolveu-se a resistência primária retardada. Apesar da diferença da presença ou não do europeu, as duas resistências são chamadas de primária, na medida em que traduzem um confronto entre povos distintos [...] A resistência intermediária revela uma acomodação entre as antigas estruturas africanas e as novas estruturas coloniais. A partir da década de 1920, assistimos a uma acomodação e a um ajustamento à nova situação na qual os africanos e os europeus participam, de forma assimétrica, é verdade, da mesma configuração social. ${ }^{4}$

O domínio colonial é tema do capítulo 7. Lopes e Arnaut explicam o êxito do dominio militar dos europeus com cinco razões: superioridade militar e logística; maior estabilidade; maiores recursos materiais e financeiros; maior conhecimento do continente; e o avanço da medicina tropical. As primeiras e principais preocupações dos europeus foram no sentido de coagir mão de obra para abastecer os portos com produtos nativos e expropriação da propriedade da terra em favor dos colonos.

A violência, o extermínio biológico e cultural são apenas algumas das facetas da colonização europeia na África. Lopes e Arnaut destacam outros elementos que necessitam ser considerados ao se analisar esse processo histórico. A colonização europeia trouxe transformações significativas

\footnotetext{
${ }^{4}$ LOPES, Ana Mónica; ARNAUT, Luís. História da África: uma introdução. Belo Horizonte: Crisálida, 2005, p. 64.

308 Revista de História Regional 16(1): 304-310, Verão, 2011
} 
para os africanos tais como: a urbanização, propagação da educação formal e formação de uma nova identidade. Esse último elemento foi fundamental no processo de luta pela independência dos países africanos. Essas independências são tema do capítulo 8, no qual os autores problematizam a forma como a temática é apontada nos livros didáticos. $\mathrm{O}$ termo independência é apresentado como forma de pensar o processo de fim de domínio de nações europeias sobre o continente africano, em contraposição ao termo descolonização. Essa última designação, também utilizada por professores de História em sala de aula, elimina vestígios da luta africana nesse processo e fortalece uma visão etnocêntrica do processo histórico em questão.

Também destacamos a importância de um item ao final livro que apresenta uma lista de filmes cuja temática é África. Os comentários que acompanham cada filme podem bem auxiliar professores numa eventual escolha para trabalhar com seus alunos. Nesse mesmo item, também pode ser encontrada uma cronologia detalhada das independências africanas, trazendo dados como ano, data, chefe de governo, principais partidos e fatos ligados ao evento. Na sequência, encontra-se uma considerável lista de sugestões bibliográficas agrupadas em torno de grandes temas que podem servir como roteiro de um estudo mais aprofundado. Também observamos a presença de alguns erros gráficos que esperamos sejam corrigidos em edições posteriores.

A obra ora resenhada cumpre bem seu papel de introduzir ao conhecimento de história da África. Pode ser bastante útil tanto a professores do Ensino Fundamental e Médio, bem como a acadêmicos das Ciências Humanas e ao público em geral. Trata-se de um trabalho introdutório que oferece ao leitor um panorama historiográfico, e não meramente informativo, do tema abordado, a África, o que pode ser destacado como ponto forte da obra. Outro elemento que merece atenção diz respeito à forma como os autores abordam o impacto da colonização europeia no continente não de forma maniqueísta, colonizador versus colonizado, mas como elementos que integram um processo histórico 
José Alexandre Silva

que cotidianamente desafia os africanos na busca de novos rumos para o seu continente.

Artigo recebido para publicação em 20/05/2010

Artigo aprovado para publicação em 20/04/2011

310 Revista de História Regional 16(1): 304-310, Verão, 2011 